\title{
Comparison of efficacy and safety of oral azithromycin and oral doxycycline in acne vulgaris
}

\author{
Marya Ahsan, Rahul Ranjan, Shalini Chandra*, Kumar Mayank
}

Department of Pharmacology, Rohilkhand Medical College and Hospital, Bareilly, Uttar Pradesh, India

Received: 03 February 2019

Revised: 21 March 2019

Accepted: 27 March 2019

*Correspondence to:

Dr. Shalini Chandra,

Email: rmch.pharmacology@ gmail.com

Copyright: (C) the author(s), publisher and licensee Medip Academy. This is an openaccess article distributed under the terms of the Creative Commons Attribution NonCommercial License, which permits unrestricted noncommercial use, distribution, and reproduction in any medium, provided the original work is properly cited.

\begin{abstract}
Background: Acne vulgaris is a chronic inflammatory disease of the pilosebaceous unit with considerable psychosocial impact. Oral azithromycin or oral doxycycline can be used for the management of moderate and severe acne vulgaris. However, there is no consensus on which antibiotic is superior and the optimal dose for management.
\end{abstract}

Methods: A prospective randomized interventional study was carried out among 120 patients of moderate to severe acne vulgaris. The patients were randomized into group A and B. While group A was prescribed oral azithromycin $500 \mathrm{mg}$ three times a week, group B was given oral doxycycline $100 \mathrm{mg}$ daily for 12 weeks. Topical clindamycin twice daily application was also given. Global Acne Grading Scale (GAGS) score was recorded at baseline and at $2^{\text {nd }}, 4^{\text {th }}, 8^{\text {th }}$ and $12^{\text {th }}$ weeks.

Results: GAGS score at baseline in azithromycin $(\mathrm{n}=53)$ and doxycycline $(\mathrm{n}=$ 55) group was $31.98 \pm 4.49$ and $30.63 \pm 3.78$ respectively ( $\mathrm{p}$ value $>0.05$ ). $83.91 \pm 6.83 \%(\mathrm{p}<0.001)$ and $81.87 \pm 6.75 \%(\mathrm{p}<0.001)$ improvement was seen in azithromycin group and doxycycline group after 12 weeks of treatment. However, there was no difference in the GAGS score between the groups at any follow-up ( $\mathrm{p}$ value $>0.05$ ). $15.09 \%$ patients in azithromycin group and $20 \%$ patients in doxycycline group reported adverse effects. The most commonly reported adverse effect was diarrhoea. All adverse effects were of 'mild' category and causality assessment was 'possible'.

Conclusions: Oral azithromycin is equally efficacious but safer alternative to oral doxycycline for the management of acne vulgaris.

Keywords: Azithromycin, Daily dosing, Doxycycline, Efficacy, Global acne grading scale, Pulse dosing

\section{INTRODUCTION}

Acne vulgaris is a chronic inflammatory disease of the pilosebaceous unit of skin which includes the hair follicle and sebaceous glands. It results from the interplay of four primary pathophysiological factors: hyperkeratinisation and hence plugging of follicles, excess sebum production, proliferation of Propionibacterium acnes and inflammation. ${ }^{1}$ Sites which are rich in pilosebaceous units such as the face, upper part of the chest and back are more prone for acne. ${ }^{2}$ It has polymorphic presentation and can include seborrhoea, non-inflammatory and inflammatory lesions. $^{3}$
Though acne vulgaris a benign self-limiting disorder, it can leave behind permanent disfiguring scarring and postinflammatory hyperpigmentation. ${ }^{4}$ This has profound impact on the psychological wellbeing of the individual. With its high prevalence in the adolescent population, acne affects the emotional and social development of the individual negatively. ${ }^{5,6}$ Considering the psychosocial ramifications of acne vulgaris, it is pertinent to treat patients effectively in order to improve their quality of life.

Oral antibiotics are used as first line of treatment in the management of moderate to severe acne vulgaris in addition to topical treatment. The most commonly 
prescribed oral antibiotics in India are doxycycline and azithromycin. $^{2,7}$ There is no conclusive evidence from clinical trials that one antibiotic is superior to the other in term of its efficacy or tolerability. Moreover, there is no consensus on the optimal dose to be employed. ${ }^{8}$

Systemic reviews and meta-analysis of conducted studies have demonstrated the beneficial effect of doxycycline in randomized placebo-controlled trials, but there are no randomized controlled trials with azithromycin. ${ }^{9}$

Thus, authors conducted a randomized controlled trial to compare the efficacy and safety of pulse therapy of $500 \mathrm{mg}$ of oral azithromycin with daily oral dosing of $100 \mathrm{mg}$ of doxycycline in the treatment of moderate to severe acne vulgaris in a tertiary care hospital in North India.

\section{METHODS}

The study was conducted as a prospective, open labelled, randomized interventional study in the Dermatology Out Patient Department of a tertiary care hospital during a period of one year among 120 patients of acne vulgaris. Institutional Ethical Committee clearance was taken prior to commencing the study. Written informed consent was taken from all the participants, and only those willing to participate were included in the study.

The Global Acne Grading System (GAGS) which takes into account both the morphology of the lesion and the area of presentation was used to calculate scores and assess severity of acne vulgaris. Scores between 1-18 were considered as mild acne, $19-30$ as moderate acne, $31-38$ as severe acne, and more than 39 as very severe acne vulgaris. ${ }^{10}$

Patients of both sexes above the age of 12 years presenting with moderate to severe acne vulgaris, i.e., GAGS score between 19-38 were enrolled in the study. The patients were randomly allocated into two groups, group A and B, following simple randomization. The first patient was allotted to group B using the lottery method and subsequent patients were placed in the two groups alternately. Patients in group A $(n=60)$ received oral azithromycin $500 \mathrm{mg}$ OD 3 days/weeks (on Monday, Tuesday and Wednesday) while patients in group B ( $\mathrm{n}=$ 60) received oral doxycycline $100 \mathrm{mg}$ OD daily.

All the patients were also prescribed topical clindamycin (1\%) twice daily. The treatment was continued for 12 weeks. Follow up was done $2^{\text {nd }}, 4^{\text {th }}, 8^{\text {th }}$ and $12^{\text {th }}$ weeks and the patients were clinically examined and evaluated for improvement in the GAGS score.

Any adverse effect reported by the patient was recorded and if required suitable intervention was done. The severity and causality assessment of adverse reaction was done using Modified Hartwig's Severity scale and WHOUMC Causality assessment respectively. ${ }^{11,12}$

\section{Statistical analysis}

Data processing was done using Statistical Package for the Social Science (SPSS), Version 23 software. Quantitative variables were expressed as mean \pm S.D and independent t-test and ANOVA was used for analysis of difference of mean between groups. P-value less than 0.05 was considered as cut-off for significance.

\section{RESULTS}

Out of 120 patients included in the study, 108 patients returned for follow up, of which 53 patients were in Group A (oral azithromycin) and 55 were in Group B (oral doxycycline). The mean age of our study population was $21.39 \pm 3.70$ years with 57 males $(52.8 \%)$ and 51 females (47.2\%).

In group A, $22(41.5 \%)$ patients had moderate acne and 31 $(58.5 \%)$ patients had severe acne. In group $\mathrm{B}, 33$ patients $(60 \%)$ had moderate acne while 22 patients $(40 \%)$ had severe acne. The mean GAGS score of both the groups was similar $(p=0.454)$. In patients on azithromycin, the GAGS score at baseline was $31.98 \pm 4.49$. There was a highly significant reduction in mean GAGS score at each followup in group A (p value <0.001). After 12 weeks of treatment with $500 \mathrm{mg}$ of oral azithromycin OD for three consecutive days in a week, the mean GAGS score had reduced from $31.98 \pm 4.49$ to $5.20 \pm 2.46$ (p value $<0.001$ ). There was $83.91 \pm 6.83 \%$ reduction in GAGS score after completing the treatment (Table 1).

Table 1: Mean GAGS score \pm SD at baseline and follow-up in group A (oral azithromycin, $n=53$ ).

\begin{tabular}{|c|c|c|}
\hline Visit & $\begin{array}{l}\text { Group A: Mean GAGS } \\
\text { score }(\mathbf{n}=\mathbf{5 3})\end{array}$ & P value \\
\hline Baseline & $31.98 \pm 4.49$ & \multirow{5}{*}{$<0.001$} \\
\hline $2^{\text {nd }}$ week & $24.73 \pm 4.05$ & \\
\hline $4^{\text {th }}$ week & $17.45 \pm 3.86$ & \\
\hline $8^{\text {th }}$ week & $10.71 \pm 3.34$ & \\
\hline $12^{\text {th }}$ week & $5.20 \pm 2.46$ & \\
\hline
\end{tabular}

$\mathrm{P}$ value $<0.001$ on ANOVA

Table 2: Mean GAGS score \pm SD at baseline and follow-up in group $B$ (oral doxycycline, $n=55$ ).

\begin{tabular}{|c|c|c|}
\hline Visit & $\begin{array}{l}\text { Group B: Mean GAGS } \\
\text { score }(n=55)\end{array}$ & P value \\
\hline Baseline & $30.63 \pm 3.78$ & \multirow{5}{*}{$<0.001$} \\
\hline $2^{\text {nd }}$ week & $24.70 \pm 3.73$ & \\
\hline $4^{\text {th }}$ week & $18.70 \pm 3.92$ & \\
\hline $8^{\text {th }}$ week & $11.72 \pm 3.73$ & \\
\hline $12^{\text {th }}$ week & $5.65 \pm 2.52$ & \\
\hline
\end{tabular}

$\mathrm{P}$ value $<0.001$ on ANOVA

In patients on doxycycline, the mean GAGS score showed a highly significant reduction at each follow-up ( $p$ value $<0.001)$. The mean GAGS score had reduced from 
$30.63 \pm 3.78$ at baseline to $5.65 \pm 2.52$ after 12 weeks of treatment ( $\mathrm{p}$ value $<0.001$ ). The reduction in GAGS score was $81.87 \pm 6.75 \%$ (Table 2).

However, on comparing the GAGS score between group A and group B at each visit, there was no statistically significant difference in the GAGS score of both the groups at any visit ( $\mathrm{p}$ value $>0.05$ ) (Figure 1$)$.

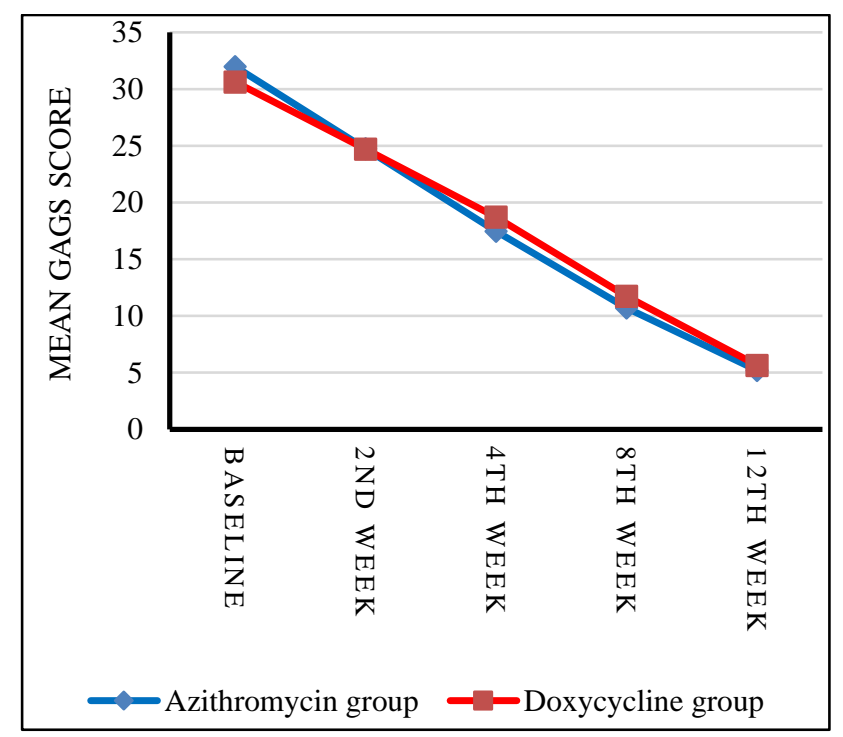

$\mathrm{P}$ value was $>0.05$ among group $\mathrm{A}$ and $\mathrm{B}$ at each visit.

Figure 1: Line diagram depicting the improvement in mean GAGS score in group A (oral azithromycin, $\mathbf{n}=$ 53 ) and group $B$ (oral doxycycline, $n=55$ ).

During the study, 19 patients (18\%) showed side effects. The side effects seen were diarrhoea, nausea, vomiting and epigastric pain. Six patients in azithromycin group while eight patients in doxycycline group complained of diarrhoea (Table 3). However, all the cases were of mild variety according to Modified Hartwig's severity scale and fell in the 'possible causality' category of WHO-UMC causality assessment.

Table 3: Number of adverse reactions in group A (oral azithromycin, $n=53$ ) and group $B$ (oral doxycycline, $\mathrm{n}=\mathbf{5 5}$ ).

\begin{tabular}{|lll|}
\hline Adverse event & $\begin{array}{l}\text { Group A } \\
(\mathbf{n}=\mathbf{5 3})\end{array}$ & $\begin{array}{l}\text { Group B } \\
(\mathbf{n}=\mathbf{5 5})\end{array}$ \\
\hline Diarrhoea & $6(11.3)$ & $8(14.55)$ \\
\hline Nausea & $1(1.89)$ & $3(5.45)$ \\
\hline Epigastric pain & $1(1.89)$ & 0 \\
\hline Total & $8(15.09)$ & $11(20)$ \\
\hline
\end{tabular}

Percentage is given in parenthesis.

\section{DISCUSSION}

Treatment of the mild variety of acne vulgaris is limited to topical regimens while systemic drugs are warranted for moderate to severe presentation of lesions. ${ }^{7}$ Oral antibiotics are usually combined with other topical agents to minimize the development of drug resistance and improve treatment efficacy. Doxycycline, minocycline, tetracycline and erythromycin are the commonly used oral antibiotics. ${ }^{8}$ Systematic review of comparative studies have found no oral antibiotic to be superior to the other in the treatment of acne vulgaris. ${ }^{9}$ In such situations antibiotic selection is driven by the tolerability profile and patterns of antimicrobial resistance. ${ }^{8}$ Recently prescription auditing of OPD prescriptions has shown that oral azithromycin in pulse dosing is also being commonly prescribed for the management of moderate to severe varieties of acne vulgaris. ${ }^{4}$ Azithromycin has great penetration power in most tissue from where it is slowly released. The elimination half-life of azithromycin approaches almost three days. This allows for once daily dosing with shortening of treatment duration in most cases. ${ }^{13}$ Though azithromycin has shown efficacy in the management of acne vulgaris, there is paucity of randomized controlled trials with azithromycin. ${ }^{1}$ Keeping this in view, we conducted this study to compare the efficacy and tolerability of $500 \mathrm{mg}$ oral azithromycin in pulse dosing with $100 \mathrm{mg}$ of oral doxycycline daily dosing for 12 weeks in the management of acne vulgaris.

In present study we included patients presenting with moderate to severe grade of acne vulgaris (GAGS score = 19-38). The mean global acne grading score of group A was $31.98 \pm 4.50$ and of group B was $30.63 \pm 3.78$ ( $\mathrm{p}$ value $=$ $0.095)$. Both the groups were comparable at baseline with respect to the global acne grading score ( $\mathrm{p}$ value $>0.05$ ) (Figure 1).

In the azithromycin group, by the $2^{\text {nd }}$ week of treatment, the mean global acne grading score had decreased to $24.73 \pm 4.05$. This decrease in GAGS score was statistically highly significant ( $\mathrm{p}$ value $<0.001$ ). This favourable response to oral azithromycin continued in the $4^{\text {th }}, 8^{\text {th }}$ and $12^{\text {th }}$ week. The reduction was highly significant at each follow-up. By the $12^{\text {th }}$ week, all the patients had only mild grade of acne vulgaris. The mean net improvement in acne severity in present study in the azithromycin group was $83.91 \pm 6.83 \%$ (Table 1 ).

Mable et al, have reported that azithromycin in pulse dosing not only improves patient compliance but is a safe and effective treatment option for all grades of acne vulgaris. The researchers have reported up to $85 \%$ clearance in lesions by the $8^{\text {th }}$ week. ${ }^{14}$ An open-label noncomparative study conducted by Kapadia et al, in Pakistan found almost $40 \%$ improvements in $82 \%$ patients by four weeks which increased to $80 \%$ clearance by the $12^{\text {th }}$ week. ${ }^{15}$

In the doxycycline group, the mean net improvement in the GAGS score was $81.87 \pm 6.75 \%$ after 12 weeks of treatment. Highly significant improvement in GAGS score was recorded at each follow-up (p value <0.001) (Table 2). Similar results were reported in other randomized trials with doxycycline. ${ }^{16}$ 
On comparing the efficacy of oral azithromycin $500 \mathrm{mg}$ pulse dosing with oral doxycycline $100 \mathrm{mg}$ daily dosing we found that both the drugs were equally efficacious in the management of acne vulgaris. There was no statistically significant difference in the mean GAGS score at any visit ( $p$ value $>0.05$ ) (Figure 1 ). Though both the drugs were equally efficacious, none of the patients were completely lesion-free at the end of 12 weeks in present study. All the patients in both the group still had a few lesions and were classified as having mild acne vulgaris (GAGS score 1-19).

Prasad et al, had prescribed a single dose of azithromycin every 10 days as the effect of azithromycin lasts for 10 days. They observed that $500 \mathrm{mg}$ of azithromycin for four days in a month $(\mathrm{n}=28)$ was equally efficacious to $100 \mathrm{mg}$ of doxycycline daily dosing $(n=22)$ in case of moderate to severe variety of acne vulgaris according to the Burke and Cunliffe scale. ${ }^{17}$ Rafiei et al, in Iran had also obtained similar results. They found that both azithromycin in pulse dosing and tetracycline in daily dosing were effective in the management of moderate to severe papulo - pustular acne vulgaris. However, they obtained a slightly higher percentage of improvement with azithromycin. ${ }^{18}$

A non-randomised controlled study among 80 patients comparing oral azithromycin pulse dosing with oral doxycycline daily dosing showed that there was $81 \%$ improvement in the azithromycin group in contrast to $66.24 \%$ improvement in the doxycycline group. ${ }^{19}$ This difference in response could be because they used a different grading system to grade acne severity. In the above study, the researchers had used the severity index described by Michaelsson et al, which grades acne, which is dependent on the morphology of the lesion and their number. Similar result was also obtained by Fernandez et al. $^{20}$

In present study, 8 patients $(15.09 \%)$ in the azithromycin group and 11 patients $(20 \%)$ in the doxycycline group reported of adverse effects. The most common adverse effects reported was diarrhoea in both the groups (Table 3). Diarrhoea was self-limiting in all cases and none of the patients had to withdraw treatment because of diarrhoea. Patients complaining of diarrhoea were advised ORS and probiotics and the condition improved in 2-3 days. The nausea and epigastric pain reported in the study group was also of mild variety and the patients did not require any intervention or stopping of treatment for these complaints. Simple measure of taking the drug after meals was sufficient in alleviating the adverse effect. According to the WHO-causality assessment, the adverse effects of diarrhoea, nausea and epigastric pain was classified as 'possible' in each case. None of the patients in our study reported phototoxicity or skin rashes in the doxycycline group.

Kapadia et al, had also reported adverse effects of heartburn and nausea in $11.4 \%$ with $500 \mathrm{mg}$ of azithromycin prescribed in pulse dosing for 12 weeks. ${ }^{15} \mathrm{~A}$ non-randomised study conducted among acne vulgaris patients in Andhra Pradesh reported that the adverse effects in the azithromycin group was negligible compared to the doxycycline group. Mild gastric upset was reported by $9.52 \%$ patients on azithromycin. However, the patients in the doxycycline group in their study had to withdraw treatment due to serious adverse effects such as oesophageal ulceration and photoonchylosis. ${ }^{19}$ Studies with azithromycin have not reported any incidence of photosensitivity even when prescribed during the summer months. ${ }^{14}$

\section{CONCLUSION}

With this study we conclude that pulse dosing (three times per week) of $500 \mathrm{mg}$ oral azithromycin was comparable in efficacy to daily dosing of $100 \mathrm{mg}$ oral doxycycline in the management of moderate to severe acne vulgaris. However, incidence of adverse effects was higher in the oral doxycycline group. Oral azithromycin can be used as a safer alternative to oral doxycycline in the management of acne vulgaris.

\section{ACKNOWLEDGEMENTS}

Authors would like to thank the Department of Dermatology, Rohilkhand Medical College and Hospital, Bareilly, Uttar Pradesh, India for their cooperation.

Funding: No funding sources

Conflict of interest: None declared

Ethical approval: The study was approved by the Institutional Ethics Committee

\section{REFERENCES}

1. Dawson AL, Dellavalle RP. Acne Vulgaris. Br Med J. 2013;346(7907):30-3.

2. Pooja M, Holla R, Girisha B, Puneeth A. A study of prescription pattern in the drug therapy of acne vulgaris at a tertiary care hospital in Mangalore, India. Int J Basic Clin Pharmacol. 2017;7(1):80-6.

3. Brar BK, Kumar S, Sethi N. Comparative evauation of dapsone $5 \%$ gel vs. clindamycin $1 \%$ gel in mild to moderate acne vulgaris. Gulf J Dermatol Venereol. 2016;23(1):34-9.

4. Adityan B, Thappa DM. Profile of acne vulgaris-A hospital-based study from South India. Indian J Dermatol Venereol Leprol. 2009;75(3):272-8.

5. Gieler U, Gieler T, Kupfer J. Acne and quality of lifeimpact and management. J Eur Acad Dermatol Venereol. 2015;29(4):12-4.

6. Loney T, Standage M, Lewis S. Not Just Skin Deep' Psychosocial Effects of Dermatological-related Social Anxiety in a Sample of Acne Patients. J Health Psychol. 2008;13(1):47-54.

7. Rathi SK. Acne vulgaris treatment: the current scenario. Indian J Dermatol. 2011;56(1):7-13.

8. Rumman N. A Review on the Advances in the Treatment of Moderate to Severe Acne Vulgaris. J Dermatol Res Ther. 2016:26-36. 
9. Bienenfeld A, Nagler AR, Orlow SJ. Oral antibacterial therapy for acne vulgaris: an evidence-based review. Am J Clin Dermatol. 2017;18(4):469-90.

10. Balaji A, Rashmi K, Devinder M. Scoring systems in acne vulgaris. Indian J Dermatol Venereol Leprol. 2009;75(3):323-6.

11. Srinivasan R, Ramya G. Adverse drug reactioncausality assessment. Int $\mathbf{J}$ Res Pharm Chem. 2011;1(3):606-12.

12. Zaki SA. Adverse drug reaction and causality assessment scales. Lung India. 2011;28(2):152-3.

13. MacDougall C. Protein synthesis inhibitors and miscellaneous antibacterial agents. In: Brunton LB, Lazo JS, Parker KL, editors. Goodman and Gilman's The Pharmacological Basis of Therapeutics. 13th edition. New York, NY: McGraw-Hill; 2018:1054-70.

14. Babu M. Case Report: Treatment With Azithromycin For Acne Vulgaris: The Current Scenario. Imperial J Interdiscipl Res. 2016;2(7):292-5.

15. Kapadia N, Talib A. Acne treated successfully with azithromycin. Int J Dermatol. 2004;43(10):766-7.

16. Kircik LH. Doxycycline and minocycline for the management of acne: a review of efficacy and safety with emphasis on clinical implications. J Drugs Dermatol. 2010;9(11):1407-11

17. Parsad D, Pandhi R, Nagpal R, Negi K. Azithromycin monthly pulse vs daily doxycycline in the treatment of acne vulgaris. J Dermatol. 2001;28(1):1-4.

18. Rafiei R, Yaghoobi R. Azithromycin versus tetracycline in the treatment of acne vulgaris. J Dermatol Treat. 2006;17(4):217-21.

19. Kumar VK. A comparative study on the efficacy and safety of oral azithromycin pulse versus doxycycline daily in the treatment of acne vulgaris. J Evid Based Med Healthcare. 2017;4(90):5410-3.

20. Fernandez-Obregon AC. Azithromycin for the treatment of acne. Int J Dermatol. 2000;39(1):45-50.

Cite this article as: Ahsan M, Ranjan R, Chandra S, Kumar M. Comparison of efficacy and safety of oral azithromycin and oral doxycycline in acne vulgaris. Int J Basic Clin Pharmacol 2019;8:913-7. 